\title{
FACTORS AFFECTING PLANT BIODIVERSITY IN THE HOMESTEADS OF RURAL AREAS UNDER PROCESS OF MODERNIZATION IN BANGLADESH
}

\author{
M.R. Islam1*, M.A. Baten' ${ }^{2}$, S.M.A. Hossain ${ }^{3}$, S.M. Afroz ${ }^{\mathbf{4}}$ and K. Naher ${ }^{\mathbf{5}}$ \\ Received 17 March 2018, Revised 10 June 2018, Accepted 26 June 2018, Published online 30 June 2018
}

\begin{abstract}
A study was carried out at selected villages in Gazipur district of Bangladesh during 20082009 to assess the changes in biodiversity of rural homesteads with modernization and factors affecting the biodiversity. Three villages were selected purposively considering their degree of modernization e.g. traditional, semi-modern and modern village and biodiversity at 40 randomly selected homesteads from each of the three villages were studied. ShannonWiener diversity index $(\mathrm{H})$ value for traditional village (1.652) was statistically similar to semi-modern village (1.373) but significantly higher $\left(\mathrm{t}=2.47^{*}\right)$ than that of modern village (1.029). It indicates that plant biodiversity is decreasing significantly with modernization and/ or urbanization. For assessing factors affecting biodiversity in the homesteads, a total of 26 factors were considered of them 15 factors had significant relationship with biodiversity. Factors like, family size, establishment of homestead, agricultural knowledge, nutritional knowledge, primary health care knowledge, environmental awareness, innovativeness, homestead area, income from homestead, savings, access to credit, disturbance of theft and predators, and utilization of modern agro-technologies had significant positive relationship; while 'fragmentation of homestead' and 'sanitation' had significantly negative relationship with homestead biodiversity. Linear multiple regression analysis showed that eight factors such as, agricultural knowledge, nutritional knowledge, environmental awareness, homestead area, income from homestead, innovativeness, homestead fragmentation and sanitation had significant contribution to homestead biodiversity. These eight significant factors explained 75.2 percent (adjusted $\mathrm{R}^{2}=0.752$ ) of the total variation in the homestead biodiversity. However, stepwise regression analysis revealed that homestead area' had the largest possible contribution (55.7\%) to variation in the homestead biodiversity, followed in descending order by agricultural knowledge (9.5\%), income from homestead $(5.0 \%)$, environmental awareness (2.9\%), sanitation (2.3\%), nutritional knowledge (1.6\%), innovativeness (1.0\%) and fragmentation of the homestead (1.0\%).
\end{abstract}

Keywords: Plant Biodiversity, Rural Homestead, Modernization, Factors Affecting Biodiversity

\footnotetext{
${ }^{1}$ Principal Scientific Officer, On-Farm Research Division (OFRD), BARI, Gazipur 1701, Bangladesh

${ }^{2}$ Professor, Dept. of Environmental Science, BAU, Mymensingh, Bangladesh

${ }^{3}$ Professor, Department of Agronomy, BAU, Mymensingh, Bangladesh

${ }^{4}$ Lecturer, Dept. of Botany, Govt. B.L. University College, Daulatpur, Khulna, Bangladesh

${ }^{5}$ Senior National Technical Advisor, ECTAD, FAO of the United Nations, Bangladesh

*Corresponding author's email: mrafiqulislam62@yahoo.com (M.R. Islam)
}

\section{Introduction}

Gazipur is one of the nearest districts to the capital city Dhaka, Bangladesh where urban development, i.e. modernization has been taking place at a faster rate and in a diverse manner. The district has a large number of national establishments such as, Bangabandhu Sheikh Mujibur Rahman Agricultural University (BSMRAU), International University of Technology (IUT), Dhaka University of Engineering and Technology (DUET), National University, Open University, Bangladesh Agricultural Research Institute (BARI), Bangladesh Rice Research Institute (BRRI),
Security Printing Press, Machine Tools Factory, Ordnance Factory and many other important institutions/organizations. Biodiversity in the area is decreasing at an alarming rate due to acquisition of lands for such establishments and flourishing urbanization. Importance of the district has increased manifolds because of its strategic position after construction of the Jamuna Bridge over the river Jamuna to link northern districts with the capital city. Population and infrastructures have been growing rapidly and remarkably in the district since 90's. Moreover, environment of the district is at threat 
due to establishment of huge number of modern residential areas and different kinds of industries such as, garments, poultry, leather, chemicals, etc. The area of modern homesteads are becoming small to smaller day by day with no or little vegetation that affecting biodiversity and livelihood as well. Homestead plays a vital role for the existence of rural people, providing them with food, fuel, fodder, timber, fish and shelter. Homestead production is the most significant system of livelihood in rural Bangladesh (Halim et al., 1996). Its management affects the production, consumption, sale and repurchase of field crops, livestock, fishes, fruits, fuels, etc. The rural economy thus depends on productivity of the natural resources, which is intimately linked with the biodiversity in the ecosystem (Rahman et al., 2009). Considering the situation as mentioned above, a study deemed necessary to assess the changes in plant biodiversity in the rural homesteads with degree of modernization as well as factors affecting the biodiversity.

\section{Materials and Methods}

Gazipur Sadar upazila was selected purposively for this piece of study. In particular, three villages of Gazipur Sadar upazila namely, Bhawal Gazipur (Traditional village) and Hatiyabo (Semimodern village) under Kaultia Union and Mariali (Modern village) under Gazipur Pourasava (municipality) constituted the study area. The degree of modernization of these villages was determined in terms of the availability of social institutions, literacy rate, public welfare services, infrastructural facilities, agricultural modernization, and settlement status. The distance from Gazipur town, universities or research institutions was also considered in this regard. Data were collected from samples, selected following a proportionate stratified random sampling technique. A village-wise list of households according to the farm categories (i.e. medium, small and landless) was prepared first. Then heads of households were selected randomly and proportionately at the ratio of 1:3:4 from medium (1.01-3.00 ha), small (0.21-1.0 ha) and landless (0.01-0.2 ha) farms, respectively, following the prevailing distribution of different farm size categories. There was no large (above 3.00 ha) farm household in any of the three villages. An equal number of samples were taken from each of the three villages. Thus, a total of 120 household heads (40 from each of the three villages) constituted sample of the study. Following measures were used in determining the plant biodiversity in the homesteads.

$$
\begin{aligned}
& \text { Inter species diversity }(\mathrm{H})=-\operatorname{Sum}\left(\mathrm{P}_{\mathrm{i}} \log \left[\mathrm{P}_{\mathrm{i}}\right]\right) \\
& \text { Where, } \mathrm{H}=\text { Shannon-Wiener index for diversity } \\
& \mathrm{P}_{\mathrm{i}}=\text { No. of individuals of one species } \\
& \text { divided by total no. of individuals in the } \\
& \text { sample. }
\end{aligned}
$$

For assessing the factors affecting plant biodiversity in the rural homesteads, a number of factors were considered from five different groups such as: i) Personal/familial factors - Age, occupation, self-education, family education, organizational membership, family size, establishment of homestead, fragmentation of homestead, agricultural knowledge, nutritional knowledge, primary health care knowledge, environmental awareness, extension media contact, innovativeness and aspiration; ii) Economic factors - Homestead area, income from homestead, savings and access to credit; iii) Socio-cultural factors - Belief and prejudice, intra and inter household conflict, disturbance of theft and predators; iv) Technological factors - Use of modern agro-technology; v) Environmental factors - Observed climate change impact, natural hazard and sanitation. Correlation of coefficient ( $r$ ) was computed for testing the relationship between selected factors and the homestead biodiversity. Correlation coefficient (r) expresses only the linear relationship but it does not indicate contribution of a particular independent variable to the dependent variable. Hence, linear multiple regression and also step-wise regression analysis was done to determine the contribution of individual factor to homestead biodiversity.

\section{Results and Discussions}

Diversity of plant species in the study villages

Analysis of species diversity in three selected villages such as, Bhawal Gazipur (Traditional village), Hatiyabo (Semi-modern village) and Mariali (Modern village) presented in Table 1 showed that diversity of plant species was higher in each of the villages. The diversity index $(H)$ value against each of the plant groups and the overall plant biodiversity index (1.832) indicates that plant biodiversity was higher in the area. 
Table 1. Species diversity of different plant groups in rural homesteads of the study villages in Gazipur Sadar upazila.

\begin{tabular}{|c|c|c|c|}
\hline Village & Plant group & Diversity index $(\mathrm{H})$ & t-value \\
\hline Bhawal & Fruit & 1.452 & \\
\hline \multirow[t]{6}{*}{ Gazipur } & Timber & 1.206 & \\
\hline & Medicinal/ ornamental & 0.854 & \\
\hline & Vegetables & 1.348 & \\
\hline & Spices & 0.684 & $\mathrm{~B} \sim \mathrm{H}=1.02$ \\
\hline & Weeds & 1.529 & \\
\hline & Total & 1.652 & $\mathrm{~B} \sim \mathrm{M}=2.47^{*}$ \\
\hline \multirow[t]{7}{*}{ Hatiyabo } & Fruit & 1.384 & $\mathrm{H} \sim \mathrm{M}=1.46$ \\
\hline & Timber & 0.795 & \\
\hline & Medicinal/ ornamental & 0.713 & \\
\hline & Vegetables & 1.251 & \\
\hline & Spices & 0521 & \\
\hline & Weeds & 1.332 & \\
\hline & Total & 1.373 & \\
\hline \multirow[t]{7}{*}{ Mariali } & Fruit & 1.016 & \\
\hline & Timber & 0.591 & \\
\hline & Medicinal/ ornamental & 0.633 & \\
\hline & Vegetables & 0.923 & \\
\hline & Spices & 0.378 & \\
\hline & Weeds & 0.845 & \\
\hline & Total & 1.029 & \\
\hline \multirow[t]{7}{*}{ All } & Fruit & 1.679 & \\
\hline & Timber & 1.074 & \\
\hline & Medicinal/ ornamental & 0.897 & \\
\hline & Vegetables & 1.556 & \\
\hline & Spices & 0.633 & \\
\hline & Weeds & 1.416 & \\
\hline & Total & 1.832 & \\
\hline
\end{tabular}

B H =Between Bhawal Gazipur and Hatiyabo; B $\sim \mathrm{M}=$ Between Bhawal Gazipur and Mariali; and $\mathrm{H} \sim \mathrm{M}=$ Between Hatiyabo and Mariali with respect to diversity index

Considering all three villages together, diversity was the highest with fruits (1.679) followed in descending order by vegetable (1.556), weeds (1.416), timber (1.074), medicinal/ornamental plants (0.897) and spice (0.633). Bashar (1999) and Mannan (2000) found that diversity of fruit species was higher compared to other plant species in rural homesteads in Gazipur. Rahman et al. (2009) reported higher diversity of fruit species in the homesteads of southwestern districts Patuakhali and Barguna. Alam and Masum (2005) also found that number of fruit species was higher compared to other plant species in the homesteads of Sandwip. The reason might be that rural households like to grow food producing species in their homesteads for subsistence need and cash income. The total plant biodiversity was higher in Bhawal Gazipur (traditional village) with an index value of 1.652, which gradually decreased in Hatiyabo (semimodern village) and Mariali (modern village) as shown in Table 1 . The diversity index value against each plant group in Bhawal Gazipur was higher than other two villages. The t-test indicated that there was no significant difference between Bhawal Gazipur and Hatiyabo with respect to diversity of different plant groups ( $t$ $=1.018$ ) but there was significant difference between Bhawal Gazipur and Mariali $(\mathrm{t}=2.47 *)$. The size of homestead and also utilization pattern of the homesteads played major role in increase or decrease in biodiversity. The size of homesteads decreased with degree of modernization of villages. The average size of the homestead in Bhawal Gazipur (0.10 ha) was significantly $\left(\mathrm{t}=0.237^{* *}\right)$ higher than that of Mariali (0.05 ha), but there was no significant difference between that of Bhawal Gazipur and Hatiyabo (0.084 ha). Fig. 1 shows that, on an average, the major portion (60- 69\%) of the homesteads in Bhawal Gazipur and Hatiyabo was occupied by vegetation while highest portion (43\%) of the homesteads was occupied by housing in Mariali. Area for housing increased significantly with degree of modernization. The average area used for housing in Mariali was significantly ( $\mathrm{t}=2.75^{* *}$ ) higher than that in Bhawal Gazipur. On the other hand, the area under vegetation in the rural homesteads decreased with increase in modernization of the 
rural areas. The area under vegetation decreased Gazipur). This is the main reason for decrease in by 9 percent in semi-modern village (Hatiyabo) plant biodiversity in the homesteads of modern and about 35 percent in modern village (Mariali) village. compared to that of traditional village (Bhawal

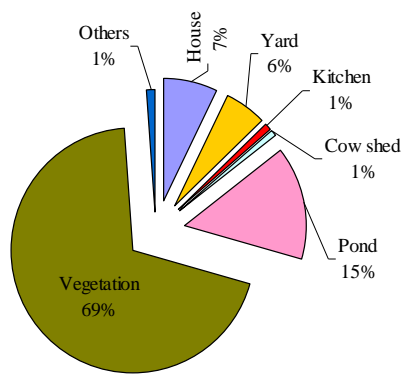

Bhawal Gazipur

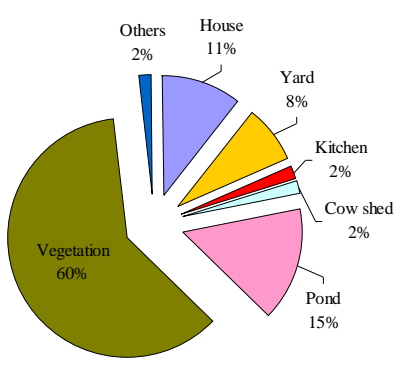

Hatiyabo

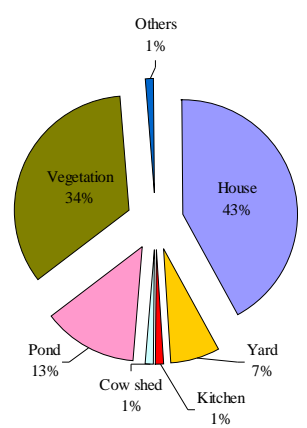

Mariali

Fig. 1. Utilization pattern of homestead area in the study villages.

Factors affecting the plant biodiversity in the rural homesteads

A total of 26 factors representing five different groups, such as: i) Familial factors, ii) Economic factors, iii) Socio-cultural factors, iv) Technological factors, and v) Environmental factors were considered to affecting homestead biodiversity. Profile of the households in selected traditional, semi-modern and modern village with respect to factors considered in the study is presented below.

\section{Bhawal Gazipur (Traditional Village)}

Higher proportions (67.5\%) of respondents (household heads) were middle aged to old. About $43.0 \%$ of them were illiterate. About $28.0 \%$ of them involved in agricultural activities only and nearly half (47.5\%) of the households were involved in both agricultural and non-agricultural activities (Table 2). Fifty per cent of the households had membership with NGOs. Proportion of large family (more than 6 members) was higher (25.0\%). Establishment of majority (80.0\%) of the households was moderately old (11-50 yrs) to old ( $>50$ years). No fragmentation occurred in $43.5 \%$ of the homesteads and $50.0 \%$ of the homesteads fragmented once. Higher proportions of the respondents had medium to high level of agricultural and primary health care knowledge but low to medium level of nutritional knowledge. About $55.0 \%$ of them had medium environmental awareness, $45.0 \%$ had low to medium extension media contact. Compared to Hatiyabo and Mariali higher proportion (10.0\%) of respondents were moderately innovative and half (50.0\%) of them had medium level of aspiration. Nearly $68.0 \%$ of the households had medium $(0.034-$ $0.1 \mathrm{ha}$ ) to large (>0.1 ha) homestead area and more than half (55.0\%) of them had medium (BDT 10001 - 50000) to high (>BDT 50000) income from the homestead. Higher proportion (45.0\%) of them had low saving and $27.5 \%$ did not have any savings. Nearly half (48.0\%) of them had medium to high access to credit. About $52.0 \%$ did not have any such belief or prejudice but $35.0 \%$ had it medium level. About $43.0 \%$ of them had very low to low level of intra \& inter household conflict. About $73.0 \%$ of households experienced medium to high level of disturbance of theft and predators. Higher proportion (62.5\%) of the households had low to medium level of utilization of modern agricultural technologies. More than half (52.5\%) of them observed medium level of climate change impact while $40.0 \%$ observed high impact. Majority (60.0\%) of them experienced medium level of natural hazards. Sanitation was poor in $40.0 \%$ of the households while $52.5 \%$ of the households had medium level of sanitation.

\section{Hatiyabo (Semi-modern village)}

Majority (77.5\%) of the respondents in Hatiyabo was young to middle aged. More than half (52.5\%) of them had secondary or higher level of education while $30.0 \%$ were illiterate. About $45.0 \%$ of households were involved in nonagricultural activities (Table 2). More than half (55.0\%) of households didn't have membership in NGOs. Establishment of majority (72.5\%) of the households was moderately old and old. No fragmentation occurred in $37.5 \%$ of the homesteads while $50.0 \%$ of the homesteads fragmented once. Half $(50.0 \%)$ of the respondents had medium and $22.5 \%$ had high level of agricultural knowledge. About 23.0\% of them had no nutritional knowledge while $70.0 \%$ had low to medium knowledge. About $75.0 \%$ of them had medium to high primary health care 
knowledge and about $63.0 \%$ had medium environmental awareness, $65.0 \%$ had low to medium extension media contact, about $68.0 \%$ of respondents had very low innovativeness and nearly half (48.0\%) of them had medium level of aspiration. More than half (55.0\%) of the households possessed small (Up to $0.033 \mathrm{ha}$ ) and medium (0.034 - $0.1 \mathrm{ha})$ homestead area and they had medium (BDT 10001-50000) to high $(>50000)$ income from the homestead. Half (50.0\%) of them had low to medium level of savings. Nearly $63.0 \%$ of them had low to medium access to credit. More than half (52.5\%) of them did not have any particular belief or prejudice. There was very low of intra \& inter household conflict among $52.5 \%$ of the households. Nearly half (47.5\%) of the households experienced high level of disturbance of theft and predators. About $43.0 \%$ of the households had no use modern agricultural technologies. More than half (55.0\%) of them observed medium level of climate change impact while $40 \%$ observed at high level. Higher proportions (57.5\%) of them experienced medium level of natural hazards. Majority (65.0\%) of the households had medium level of sanitation.

\section{Mariali (Modern village)}

Majority (70.0\%) of the respondents were middle aged to old and they (72.5\%) were involved in non-agricultural activities. More than half (57.5\%) of them had secondary or higher level of education (Table 2). Higher proportions (65.0\%) of the respondents did not have membership in NGOs. Proportion of small family (Up to 4 members) was higher (57.5\%) in Marilai. Most
(85.0\%) of the households in the village were recent establishment or moderately old. Fragmentation of the homesteads occurred once in $45.0 \%$ of the households but multiple times in $27.5 \%$. More than half (55.0\%) of the respondents had no to low level of agricultural knowledge, majority (70.0\%) had low to medium level of nutritional knowledge while about $43.0 \%$ of them had medium level of primary health care knowledge. About $57.5 \%$ of them had medium environmental awareness, $42.5 \%$ had very low extension media contact, $60.0 \%$ had very low innovativeness while more than half $(52.5 \%)$ of them had medium level of aspiration. Majority (62.5\%) of the households had small (Up to 0.033 ha) homestead area and $70.0 \%$ of them had low (Up to BDT 10000) income from the homestead. Higher proportion (40.0\%) of them had high saving (Above BDT 100000) while 37.5\% did not have any savings. Majority (62.5\%) of them had no access to credit. Majority (67.5\%) did not have any such belief or prejudice. Most (87.5\%) of them did not have any intra \& inter household conflict. More than half (52.5\%) of households did not experience disturbance of theft and predators but $32.5 \%$ experienced at medium level. Majority (77.5\%) of the households had no utilization of modern agricultural technologies. Higher proportions (67.5\%) of them observed medium level of climate change impact while only $10.0 \%$ observed high impact. More than half (55.0\%) of them experienced medium level of natural hazards. Majority (72.5\%) of them had medium level of sanitation while $20.0 \%$ of the households had high level of sanitation.

Table 2. Profile of the households in the study villages of Gazipur district.

\begin{tabular}{|c|c|c|c|c|c|c|}
\hline Factor & Category & $\begin{array}{l}\text { B. Gazipur } \\
(\%)\end{array}$ & $\begin{array}{c}\text { Hatiyabo } \\
(\%)\end{array}$ & $\begin{array}{l}\text { Mariali } \\
(\%)\end{array}$ & $\begin{array}{l}\text { Mean } \\
\text { (All) }\end{array}$ & $\begin{array}{c}\text { St. } \\
\text { Error }\end{array}$ \\
\hline Age & $\begin{array}{ll}\text { - } & \text { Young (Up to 40) } \\
\text { - } & \text { Middle age (40- 55) } \\
\text { - } & \text { Old (Above 55) }\end{array}$ & $\begin{array}{l}32.50 \\
35.00 \\
32.50\end{array}$ & $\begin{array}{l}32.50 \\
45.00 \\
22.50\end{array}$ & $\begin{array}{l}30.00 \\
35.00 \\
35.00\end{array}$ & 49.40 & 1.32 \\
\hline Occupation & $\begin{array}{l}\text { - Agriculture +Non-agriculture } \\
\text { - Agriculture } \\
\text { - Non-agriculture }\end{array}$ & $\begin{array}{l}47.50 \\
27.50 \\
25.00\end{array}$ & $\begin{array}{l}30.00 \\
25.00 \\
45.00\end{array}$ & $\begin{array}{l}17.50 \\
10.00 \\
72.50\end{array}$ & 1.75 & 0.08 \\
\hline Self education & $\begin{array}{l}\text { - No schooling } \\
\text { - Primary } \\
\text { - Secondary } \\
\text { - Higher secondary \& above }\end{array}$ & $\begin{array}{r}42.50 \\
15.00 \\
35.00 \\
7.50\end{array}$ & $\begin{array}{l}30.00 \\
17.50 \\
40.00 \\
12.50\end{array}$ & $\begin{array}{l}27.50 \\
15.00 \\
32.50 \\
25.00\end{array}$ & 6.10 & 0.46 \\
\hline Family education & $\begin{array}{l}\text { - Low education } \\
\text { - Medium education } \\
\text { - High education }\end{array}$ & $\begin{array}{r}42.50 \\
50.00 \\
7.50\end{array}$ & $\begin{array}{l}35.00 \\
50.00 \\
15.00\end{array}$ & $\begin{array}{l}20.00 \\
55.00 \\
25.00\end{array}$ & 6.49 & 0.25 \\
\hline $\begin{array}{l}\text { Organizational } \\
\text { membership }\end{array}$ & $\begin{array}{l}\text { - Have membership } \\
\text { - Don't havemembership }\end{array}$ & $\begin{array}{l}50.00 \\
50.00\end{array}$ & $\begin{array}{l}45.00 \\
55.00\end{array}$ & $\begin{array}{l}35.00 \\
65.00\end{array}$ & 0.41 & 0.05 \\
\hline Family size & $\begin{array}{l}\text { - } \text { Small (Up to 4) } \\
\text { - } \text { Medium (5- 6) } \\
\text { - } \text { Large (Above 6) }\end{array}$ & $\begin{array}{l}42.50 \\
32.50 \\
25.00\end{array}$ & $\begin{array}{l}40.00 \\
50.00 \\
10.00\end{array}$ & $\begin{array}{l}57.50 \\
27.50 \\
15.00\end{array}$ & 4.95 & 0.20 \\
\hline $\begin{array}{l}\text { Establishment of } \\
\text { the homestead }\end{array}$ & $\begin{array}{l}\text { - Recent (up to } 10 \text { yrs) } \\
\text { - Moderately old (11-50 yrs.) } \\
\text { - Old (Above } 50 \text { yrs.) }\end{array}$ & $\begin{array}{l}20.00 \\
40.00 \\
40.00\end{array}$ & $\begin{array}{l}27.50 \\
32.50 \\
40.00\end{array}$ & $\begin{array}{l}40.00 \\
45.00 \\
15.00\end{array}$ & 54.51 & 5.32 \\
\hline $\begin{array}{l}\text { Fragmentation of } \\
\text { the homestead }\end{array}$ & $\begin{array}{l}\text { - No fragmentation } \\
\text { - Fragmented once }\end{array}$ & $\begin{array}{l}42.50 \\
50.00\end{array}$ & $\begin{array}{l}37.50 \\
50.00\end{array}$ & $\begin{array}{l}27.50 \\
45.00\end{array}$ & 0.83 & 0.07 \\
\hline
\end{tabular}




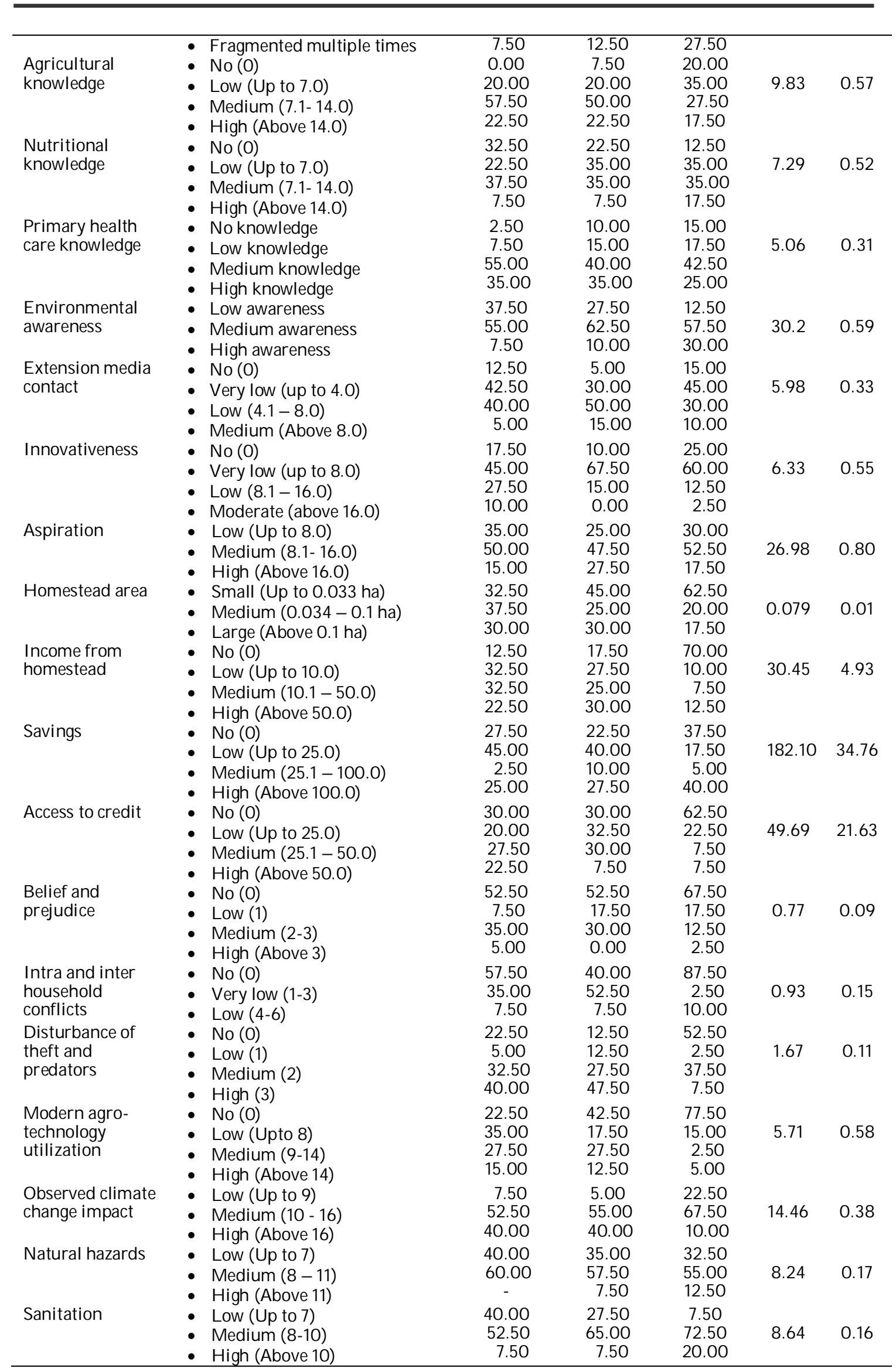


Relationship between selected factors and homestead biodiversity

Biodiversity in the rural homesteads varies from one homestead to another. The extent of biodiversity in the homesteads is likely to be influenced by different factors. Hence, attempt was made to determine and describe the relationship of selected personal/familial, economic, socio-cultural, technological, and environmental factors to homestead biodiversity through correlation analysis. The homestead biodiversity had significant positive relation with 13 factors such as: family size, establishment of the homestead, agricultural knowledge, nutritional knowledge, primary health care knowledge, environmental awareness, innovativeness, homestead area, income from homestead, savings, access to credit, disturbance of theft and predators, and modern agrotechnology utilization (Table 3). On the other hand, factors like, fragmentation of the homesteads $\left(-0.192^{*}\right)$, and sanitation $\left(-0.287^{* *}\right)$ had significantly negative relationship with homestead biodiversity. The correlation coefficients between homestead biodiversity and other factors were insignificant.

Table 3. Relationship between selected factors and homestead biodiversity.

\begin{tabular}{lc}
\hline Selected factor: (Independent variable) & Homestead biodiversity $(\mathrm{H})$ \\
\hline Age & 0.012 \\
Occupation & -0.167 \\
Self education & 0.166 \\
Family education & 0.110 \\
Organizational membership & 0.134 \\
Family size & $0.224^{*}$ \\
Establishment of the homestead & $0.509^{* *}$ \\
Fragmentation of the homestead & $-0.192^{*}$ \\
Agricultural knowledge & $0.493^{* *}$ \\
Nutritional knowledge & $0.381^{* *}$ \\
Primary health care knowledge & $0.352^{* *}$ \\
Environmental awareness & $0.218^{*}$ \\
Extension media contact & 0.010 \\
Innovativeness & $0.511^{* *}$ \\
Aspiration & 0.106 \\
Homestead area & $0.746^{* *}$ \\
Income from homestead & $0.669^{* *}$ \\
Savings & $0.283^{* *}$ \\
Access to credit & $0.199^{*}$ \\
Belief and prejudice & 0.143 \\
Intra and inter household conflicts & -0.046 \\
Disturbance of theft and predators & $0.187^{*}$ \\
Modern agro-technology utilization & $0.570^{* *}$ \\
Observed climate change impact & -0.168 \\
Natural hazards & -0.052 \\
Sanitation & $-0.287^{* *}$ \\
\hline
\end{tabular}

* Significant at 0.05 level; ** Significant at 0.01 level

Contribution of different factors to homestead biodiversity

Linear multiple regression analysis was done to determine the contribution of various factors to the homestead biodiversity. Only those factors, which had significant relationship with homestead biodiversity, were included in the regression model. The findings of the regression analysis presented in Table 4 shows that, out of 15 only 8 factors namely: fragmentation of the homestead, agricultural knowledge, nutritional knowledge, environmental awareness, homestead area, income from homestead, innovativeness and sanitation were statistically significant. The
R-square value was 0.785 and the corresponding F-value was 23.51, which was significant at .000 level (Table 3). This R-square value indicated that 78.5 percent of the total variation in the homestead biodiversity was explained by the fifteen factors included in the regression analysis. In other words, contribution of all the fifteen variables was 78.5 percent where eight significant factors contributed 75.2 percent (adjusted $\mathrm{R}^{2}=$ 0.752) while seven other insignificant factors contributed only 3.3 percent to homestead biodiversity. 
Table 4. Regression co-efficient of selected factors and the homestead biodiversity $(\mathrm{H})$.

\begin{tabular}{lcc}
\hline Independent variable: & \multicolumn{2}{c}{ Dependent variable: Homestead biodiversity(H) } \\
\cline { 2 - 3 } Selected factor & Regression co-efficient & Significance level \\
\hline Family size & 0.014 & 0.309 \\
Establishment of the homestead & 0.010 & 0.884 \\
Fragmentation of the homestead & $-0.086^{*}$ & 0.044 \\
Agricultural knowledge & $0.228^{* *}$ & 0.002 \\
Nutritional knowledge & $0.215^{* *}$ & 0.001 \\
Primary health care knowledge & 0.043 & 0.637 \\
Environmental awareness & $0.181^{* *}$ & 0.007 \\
Innovativeness & $0.182^{*}$ & 0.022 \\
Homestead area & $0.488^{* *}$ & 0.000 \\
Income from homestead & $0.284^{* *}$ & 0.000 \\
Savings & 0.038 & 0.593 \\
Access to credit & 0.053 & 0.192 \\
Disturbance of theft and predators & 0.078 & 0.206 \\
Modern agro-technology utilization & 0.014 & 0.354 \\
Sanitation & $-0.124^{*}$ & 0.021 \\
\hline $\mathrm{n}=120, \mathrm{df}=119, \mathrm{R}^{2}=0.785 ;$ Adjusted $\mathrm{R}^{2}=0.752 ; \mathrm{F}-\mathrm{value}=23.514 ; \mathrm{P}=0.000$ \\
\hline
\end{tabular}

$*$ Significant at 0.05 level; ** Significant at 0.01 level

However, it was possible that the contributions of the factors could not be expressed properly because of the inter-correlations among the factors. Thus, a step-wise multiple regression analysis was carried out. The findings of the stepwise multiple regression analysis are presented in Table 5 which showed that only eight factors namely: fragmentation of homestead, agricultural knowledge, nutritional knowledge, environmental awareness, innovativeness, homestead area,

income from homestead, and sanitation met the 0.05 significance level for entry into the regression model. So, whatever variation was in the homestead biodiversity, it was mainly due to the contribution of these eight factors. The unique contribution of each of the eight factors was also determined by taking the changes in Rsquare value occurred for entry of a particular variable in the step-wise regression model.

Table 5. Step-wise multiple regression analysis showing contribution of the selected factors to homestead biodiversity.

\begin{tabular}{lccc}
\hline Selected factors & R squared & $\mathrm{R}^{2}$ change & Variance explained (\%) \\
\hline Homestead area & 0.557 & 0.557 & 55.7 \\
Agricultural knowledge & 0.652 & 0.095 & 9.5 \\
Income from homestead & 0.702 & 0.050 & 5.0 \\
Environmental awareness & 0.730 & 0.029 & 2.9 \\
Sanitation & 0.750 & 0.023 & 2.3 \\
Nutritional knowledge & 0.766 & 0.016 & 1.6 \\
Innovativeness & 0.776 & 0.010 & 1.0 \\
Fragmentation of the homestead & 0.787 & 0.010 & 1.0 \\
\hline
\end{tabular}

The findings of the step-wise regression are presented in Table 5, which indicate that 'homestead area' had the largest possible contribution $(55.7 \%)$ to the variation in the homestead biodiversity, followed in descending order by agricultural knowledge (9.5\%), income from homestead (5.0\%), environmental awareness (2.9\%), sanitation (2.3\%), nutritional knowledge (1.6\%), innovativeness (1.0\%) and fragmentation of the homestead (1.0\%).

Finally, another linear multiple regression analysis was done involving only the eight factors found contributing significantly in the step-wise regression and results are presented in Table 6. This time the R-square value obtained was 0.771 with an F-value of 53.728, which was significant at 0.000 level. This final analysis indicated that 77.10 percent of the total variation in the homestead biodiversity was explained by the following eight factors such as: fragmentation of homestead, agricultural knowledge, nutritional knowledge, environmental awareness, innovativeness, homestead area, income from homestead, and sanitation. 
Table 6. Regression co-efficient of selected factors and the homestead biodiversity $(H)$.

\begin{tabular}{lcc}
\hline Independent variable: & \multicolumn{2}{c}{ Dependent variable: Homestead biodiversity(H) } \\
\cline { 2 - 3 } Selected factors & Regression co-efficient & Significance level \\
\hline Homestead area & $0.474^{* *}$ & 0.002 \\
Fragmentation of the homestead & $-0.103^{*}$ & 0.033 \\
Income from homestead & $0.268^{* *}$ & 0.000 \\
Agricultural knowledge & $0.168^{* *}$ & 0.000 \\
Nutritional knowledge & $0.173^{* *}$ & 0.004 \\
Environmental awareness & $0.191^{* *}$ & 0.003 \\
Innovativeness & $0.155^{*}$ & 0.023 \\
Sanitation & $-0.157^{* *}$ & 0.001 \\
\hline $\mathrm{n}=120, \mathrm{df}=119, \mathrm{R}^{2}=0.771 ;$ Adjusted $\mathrm{R}^{2}=0.756 ;$ F-value $=53.728 ; \mathrm{P}=0.000$ \\
\hline
\end{tabular}

* Significant at 0.05 level ; ** Significant at 0.01 level

The regression coefficient against homestead area $\left(0.474^{* *}\right)$ indicates that it had significant positive contribution to homestead biodiversity (Table 6). It means biodiversity increased with increase in area of the homestead. Larger area of the homestead facilitates growing more species of plants of different kinds i.e. fruits, vegetables, timber, medicinal, ornamental etc. Various weeds (particularly herbs and shrubs) grow there spontaneously and many of these plants have medicinal value while some are used as vegetables. More space in the homestead allows rearing cattle, goat, poultry and other animals like cat, dog, birds etc., and in this way biodiversity of the homesteads increased.

There is a positive consequence in between plant diversity and farm categories i.e. species richness and diversity increased as the farm size increased proportionately (Rahman et al., 2009). Marked variation in species richness and diversity was found in the homestead of different farm categories. The highest types of species (108) were found in the large farm whereas the lowest types of species (71) were found in the small farm category (Alam and Masum, 2005). So, adequately large homesteads are prerequisite for maintaining a higher biodiversity. Fortunately there are still some medium $(0.031-0.1 \mathrm{ha})$ and large (above $0.1 \mathrm{ha}$ ) homesteads in the selected villages that might have contributed a higher biodiversity in the area. But the proportion of small homesteads is increasing alarmingly in the area particularly in Mariali (modern village) mainly due to fragmentation for inheritance and urbanization in the area. Abrupt increase in price of land in the area is also another important reason that newly established homesteads are mostly small in size. Obviously the number of homesteads will increase in future with increase in population. Fragmentation of existing homesteads or conversion of crop lands into homesteads is the possible option to meet the housing requirements for the increasing population and both options are harmful to biodiversity. To protect the existing biodiversity through fragmentation of the homesteads and establishing of new homesteads in crop lands, a multi-storied housing plan is very essential. Government may impose law in this regards and provide loan and other facilities so that households can construct multi-storied house sufficient for its members. Government, NGOs and other financial institutions can take initiative to construct multi-storied housing and other infrastructures in rural areas all over the country particularly in areas adjacent to district and upazila towns. Thus, a long term 'rural infrastructure development plan' is demand of the time.

The regression coefficient for fragmentation of homestead $\left(-0.103^{*}\right)$ showed a significant negative contribution to homestead biodiversity (Table 6). The size of the rural homesteads becoming small to smaller mainly due to fragmentation i.e. distribution of the property among inherits. Construction of new houses after fragmentation usually require removal of some trees and other plants, while small area may not allow growing large trees (fruits/timber) and rearing livestock and poultry which ultimately reduce biodiversity. If fragmentation of the rural homesteads continues, time will come when further fragmentation will be impossible and there will be little or no space for growing plants or rearing livestock in the homesteads. Due to fragmentation of homestead, it is becoming increasingly difficult to make rational use of available homestead area for agroforestry and vegetable production (Dasgupta et al., 1990). In some cases, particularly in Mariali, households sold out their homesteads and adjacent crop lands into small housing plots for getting a high price. Before selling, they remove almost all the trees/plants from these homesteads or lands to divide it into small plots. In this way fragmentation of homesteads and lands is affecting biodiversity negatively. So, fragmentation of rural homesteads should be minimized as much as possible for conserving biodiversity. It requires awareness building among the people and huge motivational works for a better future for next generation. 
The regression coefficient for income from homestead $\left(0.268^{* *}\right)$ showed a significant positive contribution to homestead biodiversity (Table 6). It is better to say, homestead biodiversity had significant positive contribution to income from the homestead. It was found that income from homestead had significant positive relationship with homestead area $\left(r=0.524^{* *}\right)$. Again, biodiversity was higher with larger homesteads i.e. large homesteads contained higher number of plants of different species (fruits, timber, vegetables, spices etc.) and also contained livestock, poultry and fishes and all these contributed to higher income. The regression analysis showed that agricultural knowledge had significant positive contribution $\left(0.168^{* *}\right)$ to homestead biodiversity (Table 6$)$. It is quite likely that households having higher agricultural knowledge are able to grow different trees (fruits, timber, medicinal and ornamental), vegetables, spices etc. more efficiently and they are also able to rear livestock, poultry or cultivate fish more profitably. In other words, households involved in growing crops, trees; cultivation of fish or rearing livestock might have higher knowledge about agriculture.

It revealed from the regression analysis that nutritional knowledge also had significant positive contribution $\left(0.173^{* *}\right)$ to homestead biodiversity (Table 6). Actually rural households of all categories grow at least some fruit trees in their homesteads mainly for family consumption and for earning some money. In spite of fuel crisis very few farmers were found to grow trees primarily for fuel. Farmers were found to prefer fruit trees as they could get both fruit and fuel (fodder in some cases) from trees (Abedin and Quddus, 1988). Households with no or low education have low knowledge about nutrition i.e. they do not know exactly which fruit is rich in which vitamin or deficiency of which vitamin cause which disease; but they know that fruits, vegetables, fish, egg, milk, meat etc. are very essential for good health and these items have good market value. As such rural households grow these items either for own consumption or for earning money which ultimately increases biodiversity in the homesteads.

Environmental awareness of rural homesteads had significant positive contribution (0.191**) to homestead biodiversity (Table 6). Rural households usually grow medium to large trees in their homesteads with a view to keep their homesteads cool, protect houses from wind storm, reduce soil erosion etc. in addition to have fruits, timber and fuel. They grow plants and animals for family nutrition and health and also for beautification of the homesteads and all these contribute to homestead biodiversity. Rural households were more or less aware of harmful effects of deforestation, pollution of soil, water and air through chemical fertilizers and pesticides and also aware about harmful effects of cigarette and polythene might be due to campaign through mass media like, TV and radio or their organizational memberships i.e. membership in NGOs as there was significant relationship between organizational membership and environmental awareness $\left(\mathrm{r}=0.241^{* *}\right)$. Islam (2005) observed that 'SAIP', 'World Vision Bangladesh' and 'Caritas' launched separate programme for building awareness on environmental issues through training programme on a regular basis to their beneficiaries. This might be the reason of increased environmental awareness of their beneficiaries.

The regression coefficient for innovativeness $\left(0.155^{*}\right)$ showed a significant positive contribution to homestead biodiversity (Table 6). Rural households who were more innovative adopted different technologies earlier. There was significant positive correlation between innovativeness and agricultural knowledge $(\mathrm{r}=$ $\left.0.276^{* *}\right)$, nutritional knowledge ( $\left.\mathrm{r}=0.415^{* *}\right)$, environmental awareness $\left(r=0.403^{* *}\right)$ and modern agro-technology utilization $(r=0.519 * *)$. It might be said that rural households who were more innovative had higher knowledge about agriculture and nutrition, they were more aware about environmental issues and adopted different modern agro-technologies particularly modern species/variety of vegetables, fruits, timber and exotic breeds of livestock, poultry, etc. So, it is logical that innovative households contain higher number of species of plants and animals i.e. higher biodiversity.

The regression analysis revealed that sanitation had significant negative $\left(-0.157^{* *}\right)$ contribution to homestead biodiversity (Table 6). It is better to say, higher biodiversity in the homestead contributes to lower sanitation. Presence of higher number of trees, livestock, poultry, etc. produce higher amount of organic wastes and improper management of these wastes reduces sanitation of the homestead. Dense vegetation and bushes in the homestead might allow households particularly children for defecation or urination at open place or open latrine, which also hamper sanitation. Again, heavy shade due to higher number of large trees might make the homestead dumpy, which is also harmful from sanitation point of view.

In view of the significant contributions of the above mentioned factors to the variations in the biodiversity of rural homesteads, it can be concluded that each of these eight factors namely, homestead area, agricultural knowledge, income from homestead, environmental awareness, nutritional knowledge, sanitation, innovativeness and fragmentation of homestead had a significant effect on the homestead biodiversity. 


\section{References}

Abedin, M.Z. and Quddus, A. 1990. Household fuel situation, home gardens and agroforestry practices at six agro-ecologically different locations of Bangladesh. In: Abedin, M.Z., Lai, C.K. and Ali, M.O. (eds.) Homestead Plantation and Agroforestry in Bangladesh, Proc. National Workshop held during July 17-19, 1988 in Joydebpur, Gazipur, Bangladesh. pp. 19-36.

Alam, M.S. and Masum, K.M. 2005. Status of Homestead Biodiversity in the Offshore Island of Bangladesh. Res. J . Agric. Bio. Sci. 1(3): 246-253.

Bashar, M.A. 1999. Home garden Agroforestry: Impact on biodiversity conservation and household food security (A case Study of Gazipur District, Bangladesh). M. Sc. Thesis, Centre for Intl. Env. \& Dev. Stud., Noragic, Agril. Univ., Norway. pp. 21-34.

Dasgupta, S., Rahman, M.M., Rahman, M.M., Rahman, M.L. and Azad, A.K. 1990. Agroforestry Status in Homestead Area of Vaskarkhilla FSR Site, Kishoreganj. In: Abedin, M.Z., Lai, C.K. and Ali, M. O. (eds.) Homestead Plantation and Agroforestry in Bangladesh, Proc. National Workshop held during July 17-19, 1988 in Joydebpur, Gazipur, Bangladesh. p. 161.
Halim, A., Hossain, M.A., Rahman, M.M., Alam, A.B.M.M., Hossain, S.M.A., Sobhan, M.A. and Islam, M.M. 1996. Management of homestead environment. Environment education training module for agricultural extension workers in Bangladesh. Graduate Training Institute, Bangladesh Agricultural University, Mymensingh. pp. 195-200.

Islam, M.N. 2005. GO-NGO Collaboration for Sustainable Livelihood of Garo Women in Bangladesh. Ph. D. Thesis, Department of Agricultural Extension Education, Bangladesh Agricultural University, Mymensingh. pp. 63-103.

Mannan, M.A. 2000. Plant-Biodiversity in the Homesteads of Bangladesh and Its Utilization in Crops Improvement. Ph. D. Thesis, Department Genetics and Plant Breeding, Bangabandhu Sheikh Mujibur Rahman Agricultural University, Salna, Gazipur. pp. 27-59.

Rahman, M.M., Atiqullah, M. and Miah, M.G. 2009. Homestead Plant Biodiversity in the South-Western Costal Zone of Bangladesh: Way Forward to Identification, Utilization and Conservation. National Food Policy Capacity Strengthening Programme (NFPCSP). Food and Agriculture Organization of United Nations (FAO), Dhaka, Bangladesh. pp. 1-25. 